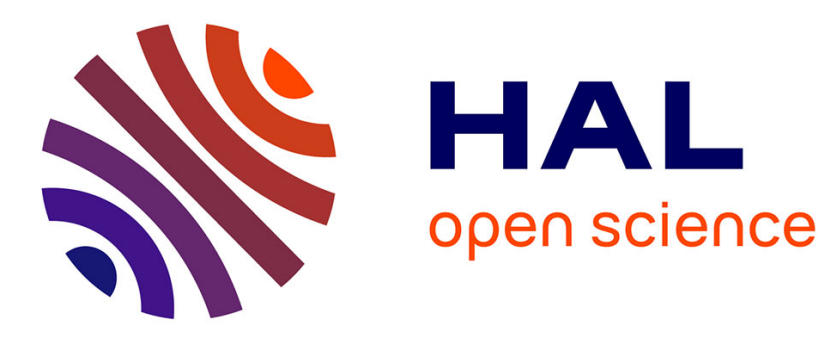

\title{
Uniaxial compression test on ceramic green compact with bending consideration using digital image correlation
}

Caiuã Caldeira de Melo, Matheus Furlan, François Hild, Nicolas Schmitt, Rodrigo B. Canto

\section{To cite this version:}

Caiuã Caldeira de Melo, Matheus Furlan, François Hild, Nicolas Schmitt, Rodrigo B. Canto. Uniaxial compression test on ceramic green compact with bending consideration using digital image correlation. Powder Technology, 2020, 376, pp.136-148. 10.1016/j.powtec.2020.08.002 . hal-02910819

\section{HAL Id: hal-02910819 https://hal.science/hal-02910819}

Submitted on 3 Aug 2020

HAL is a multi-disciplinary open access archive for the deposit and dissemination of scientific research documents, whether they are published or not. The documents may come from teaching and research institutions in France or abroad, or from public or private research centers.
L'archive ouverte pluridisciplinaire HAL, est destinée au dépôt et à la diffusion de documents scientifiques de niveau recherche, publiés ou non, émanant des établissements d'enseignement et de recherche français ou étrangers, des laboratoires publics ou privés. 


\title{
Uniaxial compression test on ceramic green compact with bending consideration using digital image correlation
}

\author{
Caiuã Caldeira de Melo ${ }^{1}$, Matheus Furlan², François Hild ${ }^{3}$, Nicolas Schmitt $^{3}$, Rodrigo \\ Bresciani Canto ${ }^{1,2, *}$ \\ ${ }^{1}$ Federal University of São Carlos (UFSCar), Graduate Program in Materials Science and Engineering \\ (PPGCEM), 13565-905 São Carlos/SP, Brazil \\ ${ }^{2}$ Federal University of São Carlos (UFSCar), Department of Materials Engineering (DEMa), 13565-905 \\ São Carlos/SP, Brazil \\ ${ }^{3}$ Université Paris-Saclay, ENS Paris-Saclay, CNRS, LMT - Laboratoire de Mécanique et Technologie \\ 4 avenue des Sciences, 91190 Gif-sur-Yvette, France
}

\begin{abstract}
A uniaxial compression test was performed on a green compacted alumina powder. Using Digital Image Correlation (DIC), displacement fields of two perpendicular surfaces of the specimen were measured showing unavoidable bending effect. A constitutive model was calibrated through three Finite Element Model Updating approaches. First, an analysis was performed using average axial strains assessed via DIC and resultant forces to identify the constitutive model. Then, a plane stress analysis was conducted out using the displacements of the boundaries of the regions of interest for each camera separately to obtain the sought parameters. Last, a 3D analysis was carried out using the multi-point constraint method to link displacement fields of both surfaces. Because of bending, the first two approaches give rise to two sets of different parameters. The analysis that considers the $3 \mathrm{D}$ nature of bending leads to the set of parameters with the highest degree of confidence. Keywords: Uniaxial compression test, Bending, Green compact, DIC, FEMU.
\end{abstract}

\footnotetext{
${ }^{*}$ Corresponding author. Email: rbcanto@ufscar.br. Address: 13565-905, Rodovia Washington Luís, São Carlos/SP, Brazil
} 


\section{Introduction}

Uniaxial compression is a well-known experimental procedure to characterize the mechanical properties of metals, polymers, and ceramics, by establishing the relationship between the uniaxial stress state prescribed by the loading condition and the induced triaxial strain state [1]. For an ideal uniaxial compression test, a uniform stress state is expected to arise within the specimen. However, some artifacts may jeopardize this usually assumed stress homogeneity [2, 3]. Features of the test such as the lack of parallelism of the platens and eccentric forces on the specimen usually result in non-uniform stress states. Further, geometrical imperfections of the sample geometry and inhomogeneity may lead to similar issues.

Ceramics are brittle materials, which makes it hard to ensure the desired geometry of the specimen by traditional shaping processes. The difficulty of designing some geometries of specimen and fixture parts to reach the desired stress states may lead to spurious data and erroneous identification of material parameters [4]. As reported in the ASTM C1424-10 standard: "actual studies of the effect of bending on the compressive strength distributions of advanced ceramics do not exist" [5]. This paper aims to propose a procedure that will automatically account for such imperfections.

The accuracy of the material models depends on the calibration quality from mechanical tests. Green compacts are commonly characterized by using mechanical tests such as uniaxial compression and Brazilian tests from which material parameters are identified [6-11]. The classical identification methods of mechanical parameters uses fitting approaches from stressstrain curves obtained in these mechanical tests. For compression tests, the stress distribution is commonly assumed as homogeneous and calculated as the ratio of measured force and cross-sectional area of the specimen. The strains are evaluated from the use of the cross-head displacement (when the machine compliance is negligible with respect to that of the tested sample), strain gauges, optical or mechanical (contacting) extensometers. For verification 
purposes of the stress and strain state distributions in the specimen for uniaxial compression, multiple strain gauges are installed on the lateral surfaces of the specimen or a verification test specimen is utilized [1, 5]. The difference in measured axial strain values is evidence of imperfect mechanical tests. As the fracture of ceramic materials may be catastrophic, it is not recommended to use conventional contacting extensometers.

Full-field measurement methods enrich the identification and calibration of constitutive models [12. In the present study, FE-based digital image correlation (DIC) [13, 14] was used. In the earlier implementations of DIC, local registrations of small interrogation windows were performed [15, 16]. Global approaches were introduced later on [17, 18], often based on finite element discretizations of the measured displacement fields [19]22]. Measuring displacement fields may provide a better understanding of mechanical tests. One way of better understanding tests is via numerical simulations. For instance, Finite Element Model Updating (FEMU) is a widely applied identification method [23]. It consists in minimizing the difference between measured and computed variables such as loads [24, 25], displacements [25, 26], temperatures [27], by an iterative scheme for optimizing the model parameters. The combination of FEMU and DIC techniques has achieved satisfactory results in the calibration of constitutive models [28 34]. Via DIC analyses, Montilha et al. [11] determined the elastic parameters in an alumina green compact and observed dilatancy for the tested material in uniaxial compression. Another route usually consists in utilizing more complex triaxial testing cells to assess dilatancy [35].

In this paper, an analysis of a uniaxial compression test on a compacted alumina specimen (Section 2) was performed using DIC. Images were captured for two perpendicular surfaces of a cuboid specimen. The degrees of freedom related to the vertical displacement of the common edge in both faces will be coupled by a multi-point constraint approach [36] (Section 3). To the best of the authors' knowledge, such technique was not reported in the 
literature for DIC analyses. Despite the non-homogeneous strain field obtained in the studied uniaxial compression test, it is possible to calibrate some parameters of an elastoplastic, nonlinear hardening Drucker-Prager model [37, 38] by using three different FEMU-F analyzes (Section 44). Section 5 describes the experimental and numerical results and shows that using two of the developed approaches, bending effects may be quantified and accounted for in the calibration of the parameters of an elastoplastic model.

\section{Material, experimental procedure and modeling}

An atomized alumina $\left(\mathrm{Al}_{2} \mathrm{O}_{3}\right)$ powder [11, 39] was used to make the cuboid specimen. This manufacturing process was divided into three steps, namely, (i) isostatic pressing of the alumina powder at a minimum pressure to handle the sample, (ii) manual sanding, and (iii) final isostatic pressing. In the first step, the specimen was preformed in an isostatic AIP CP360 press. The chosen pressure for this step was $10 \mathrm{MPa}$, which was enough to press green compacts that are not too brittle to handle, and prevent major distortions in the geometry of the specimen. In the second step, the remaining geometric distortions were corrected by sanding the specimen. Last, the specimen was recompacted at $100 \mathrm{MPa}$ The specimen was not sintered (green compact). Table 1 summarizes the final geometry of the studied specimen and some characteristics.

Table 1 Basic characteristics/properties of the specimen

\begin{tabular}{|c|c|c|c|c|c|c|}
\hline \multirow[t]{2}{*}{ Material } & \multicolumn{3}{|c|}{ Dimensions [mm] } & \multicolumn{2}{|c|}{ Mass Density $\left[\mathrm{g} / \mathrm{cm}^{3}\right]$} & \multirow[t]{2}{*}{ Average grain size $[\mu \mathrm{m}]$} \\
\hline & Thickness & Width & Height & Apparent & Fully-dense & \\
\hline Compacted alumina powder & 20.3 & 20.3 & 50.8 & 2.35 & $3.74^{*}$ & $75^{* *}$ \\
\hline
\end{tabular}

Figure 1(a) shows the tested specimen between the platens of the testing machine. A 
random speckle pattern was sprayed onto the observed surfaces to increase the number of gray levels and contrast in the image, and make DIC measurements possible.

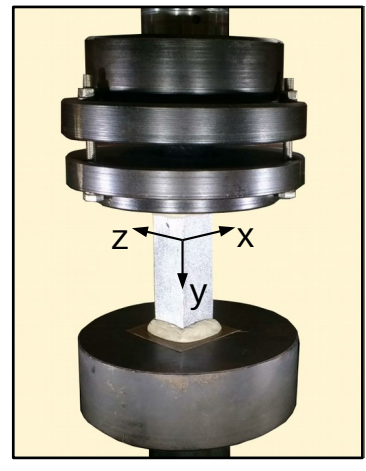

(a)

\section{Specimen}

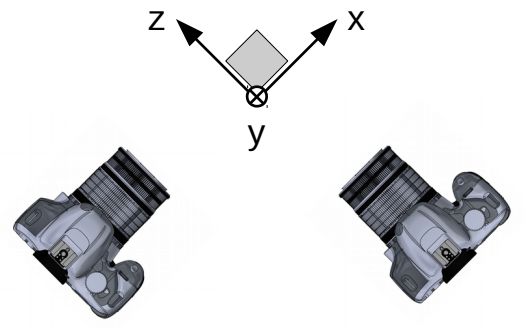

Camera 1 Model T5i
Camera 2 Model T5i

(b)

Figure 1 Experimental setup. (a) Specimen $\left(20.3 \times 20.3 \times 50.8 \mathrm{~mm}^{3}\right)$ between the testing machine platens, and (b) upper schematic view of the camera disposition to image two adjacent lateral surfaces

71 The images were simultaneously acquired with two cameras monitoring two adjacent 72 lateral surfaces (Fig. 1(b)). The hardware parameters of the optical setup are gathered in 73 Table 2 . 
Table 2 DIC hardware parameters

\begin{tabular}{|l|l|}
\hline \hline Cameras & CANON T5 Rebel \\
Definition (raw) & $3456 \times 5184$ pixels (Bayer pixels) \\
Gray Levels amplitude & 8 bits \\
Lens & CANON 100-mm macro \\
Aperture & $f / 5.6$ \\
Field of view & $40 \times 60 \mathrm{~mm}^{2}$ \\
Image scale & $11.6 \mid 10.9 \mathrm{\mu m} /$ pixel (camera $1 \mid 2)$ \\
Stand-off distance & $27 \mathrm{~cm} \mid 25 \mathrm{~cm}$ (camera $1 \mid 2)$ \\
Image acquisition rate & $0.05-0.17 \mathrm{fps}$ \\
Exposure time & $1 / 60 \mathrm{~s}$ \\
Patterning technique & sprayed black paint \\
Pattern feature size $\sharp$ & 4 pixels $(\mathrm{B} / \mathrm{W})$ \\
\hline \hline aluated as full width at half maximum of autocorrelation function
\end{tabular}

The test was performed in a series of loading-unloading cycles on a servohydraulic MTS Bionix testing system equipped with a $15 \mathrm{kN}$ capacity load cell. To reduce the problems related to the lack of parallelism between the loaded surfaces, an epoxy resin was applied on the upper and lower parts of the specimen (Fig. 1). The testing procedure, shown in Fig. 2, consisted of four loading-unloading cycles, followed by a final loading until the force started to decrease. A cross-head speed of $0.1 \mathrm{~mm} / \mathrm{min}$ was selected, and a preload of $30 \mathrm{~N}$ was applied. The number of acquired pictures was equal to 88 for both perpendicular faces (Fig. 1). 


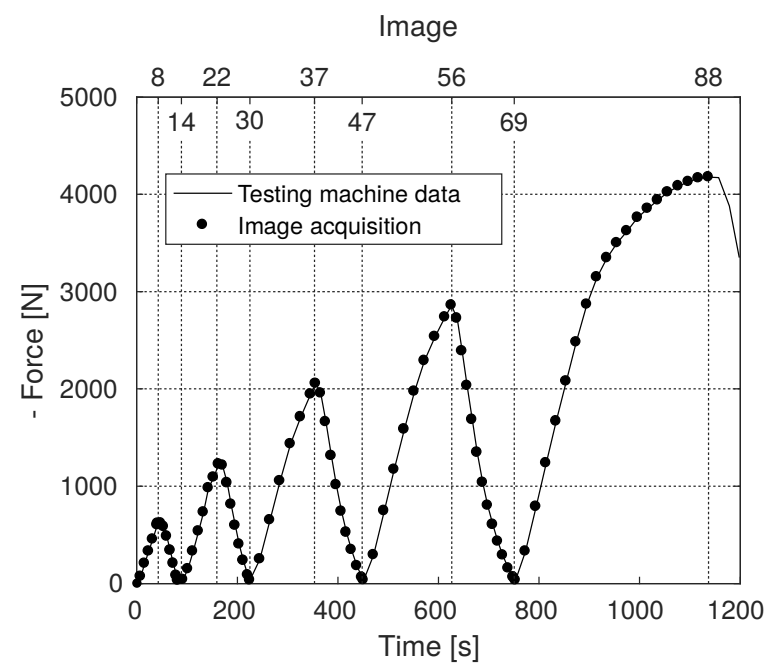

Figure 2 Force history showing the image acquisition instants (depicted with solid circles)

The original elastoplastic Drucker-Prager model with nonlinear hardening was chosen to represent the mechanical behavior of green compacted alumina since this powder (i.e., unsintered ceramic) has a ductile behavior when considered as a continuous medium [11. Elasticity was considered as isotropic and linear, characterized by Young's modulus and Poisson's ratio. This model considers a pressure-dependent yield surface, with a linear form when expressed in terms of pressure $p$ and von Mises stress $q$. The equation of the yield locus is expressed with two parameters, namely, the angle of friction $\beta$ and an intercept (i.e., the so-called material cohesion $d$ ).

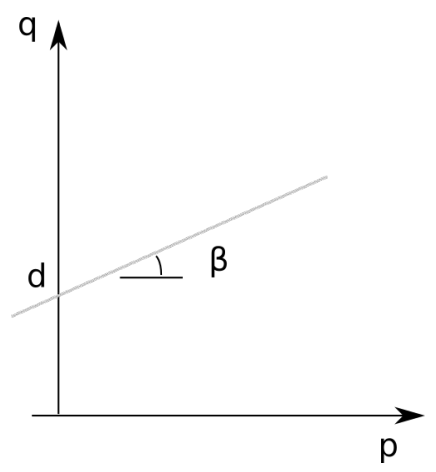

Figure 3 Original Drucker-Prager yield surface represented in a pressure $p$ vs. von Mises stress $q$ plane 
The hardening response was modeled with Voce's law 40]

$$
\sigma_{a x}=\sigma_{\infty}-\left(\sigma_{\infty}-\sigma_{y}\right) \exp \left(-b \epsilon_{a x}^{p}\right)
$$

where $\sigma_{a x}$ is the axial stress, $\sigma_{\infty}$ the compressive strength, $\sigma_{y}$ the yield stress, $b$ a hardening coefficient, and $\epsilon_{a x}^{p}$ the axial plastic strain. One may note that the parameters $d$ and $\sigma_{y}$ are linearly dependent. For the analysis in this work, the identification (described in Section 4) was not sensitive to the Poisson's ratio $\nu$ and the friction angle $\beta$. Both values were taken from the literature [11, 39], respectively as $\nu=0.13$ and $\beta=55^{\circ}$.

\section{Digital Image Correlation and multi-point constraint}

Global digital image correlation aims to find the displacement field $\boldsymbol{u}$ that minimizes globally the difference of the gray levels between a reference image $f$ and a deformed image $g$ corrected by the measured displacement. The corresponding (gray level) conservation law is written with the following cost function

$$
\eta^{2}=\sum_{i}^{N_{i}}\left[f\left(\boldsymbol{x}_{i}\right)-g\left(\boldsymbol{x}_{i}+\boldsymbol{u}_{i}\right)\right]^{2}
$$

where $N_{i}$ is the number of pixels in the region of interest (ROI). To ensure a good conditioning of the minimization, the displacement of the $i$-th pixel $\boldsymbol{u}_{i}$ is represented by a set of degrees of freedom via finite element (FE) shape functions

$$
\boldsymbol{u}_{i}=\boldsymbol{u}\left(\boldsymbol{x}_{i}\right)=\sum_{j}^{N_{j}} \boldsymbol{\phi}_{j}\left(\boldsymbol{x}_{i}\right) a_{j}
$$

where $a_{j}$ are the (unknown) nodal displacements, and $\phi_{j}\left(x_{i}\right)$ the finite element shape function [41]. In the present case, linear triangular elements were selected so that the corre- 
sponding shape functions were linear with respect to the spatial coordinates.

To solve the minimization problem, an iterative scheme is proposed where the degrees of freedom $\{\boldsymbol{a}\}$ are decomposed as a current guess $\{\boldsymbol{a}\}^{(n)}$, and incremental updates $\{\delta \boldsymbol{a}\}$

$$
\{\boldsymbol{a}\}^{(n+1)}=\{\boldsymbol{a}\}^{(n)}+\{\delta \boldsymbol{a}\}
$$

Linearizing the summand of the DIC cost function given in Eq. (2), the solution is found by solving the following linear system [13, 16, 42]

$$
[\boldsymbol{M}]\{\delta \boldsymbol{a}\}=\{\boldsymbol{b}\}
$$

where

$$
M_{j k}=\sum_{i=1}^{N_{i}}\left(\boldsymbol{\nabla} f\left(\boldsymbol{x}_{i}\right) \cdot \boldsymbol{\phi}_{j}\left(\boldsymbol{x}_{i}\right)\right)\left(\phi_{k}\left(\boldsymbol{x}_{i}\right) \cdot \boldsymbol{\nabla} f\left(\boldsymbol{x}_{i}\right)\right)
$$

and

$$
b_{j}=\sum_{i=1}^{N_{i}}\left(\nabla f\left(\boldsymbol{x}_{i}\right) \cdot \boldsymbol{\phi}_{j}\left(\boldsymbol{x}_{i}\right)\right)\left(f\left(\boldsymbol{x}_{i}\right)-\tilde{g}\left(\boldsymbol{x}_{i}\right)\right]
$$

where $\tilde{g}\left(\boldsymbol{x}_{i}\right)=g\left(\boldsymbol{x}+\boldsymbol{u}^{(n)}(\boldsymbol{x})\right)$.

Constraint conditions, commonly applied in the FE method [43], are used to introduce additional relationships among degrees of freedom or couple separate regions together. To couple the common regions observed by both cameras, the multi-point constraint (MPC) with the linear transformation method [36] was used herein. Alternative constraint procedures such as Lagrange multipliers and penalty methods could also be used. The Lagrange multiplier approach increases the number of equations of the linear system, while the selected method requires less effort than the others to assemble the global equations. On the other hand, the penalty method conserves the number of system variables but may lead to an ill-conditioned set of equations [44]. 
From Eq. (5), the following linear system is written to determine the degrees of freedom from the separate image acquisitions independently

$$
\left[\begin{array}{cc}
{\left[\boldsymbol{M}^{c 1}\right]} & \mathbf{0} \\
\mathbf{0} & {\left[\boldsymbol{M}^{c 2}\right]}
\end{array}\right]\left\{\begin{array}{l}
\left\{\delta \boldsymbol{a}^{c 1}\right\} \\
\left\{\delta \boldsymbol{a}^{c 2}\right\}
\end{array}\right\}=\left\{\begin{array}{c}
\left\{\boldsymbol{b}^{c 1}\right\} \\
\left\{\boldsymbol{b}^{c 2}\right\}
\end{array}\right\}
$$

where $c 1$ and $c 2$ designate the two cameras. It is worth noting that the units of the nodal displacements $\left\{\boldsymbol{a}^{c 1}\right\}$ and $\left\{\boldsymbol{a}^{c 2}\right\}$ are pixels, which can have different physical dimensions for each camera, depending on the lens and the magnification. To have a better global perspective of the system variables, the pixel quantities are converted into usual units of length

$$
\left\{\delta \overline{\boldsymbol{a}}^{c}\right\}=\left\{\delta \boldsymbol{a}^{c}\right\} \pi^{c} \text { and }\left\{\overline{\boldsymbol{b}}^{c}\right\}=\left\{\boldsymbol{b}^{c}\right\} \pi^{c}
$$

where $\pi^{c}$ is the physical size of one pixel for a photographed face by camera $c$. Converting the displacements and also the right-hand terms $\left\{\boldsymbol{b}^{c}\right\}$, the linear system (8) is rewritten as

$$
\left[\begin{array}{cc}
{\left[\boldsymbol{M}^{c 1}\right]} & {[\mathbf{0}]} \\
{[\mathbf{0}]} & {\left[\boldsymbol{M}^{c 2}\right]}
\end{array}\right]\left\{\begin{array}{l}
\left\{\delta \overline{\boldsymbol{a}}^{c 1}\right\} \\
\left\{\delta \overline{\boldsymbol{a}}^{c 2}\right\}
\end{array}\right\}=\left\{\begin{array}{l}
\left\{\overline{\boldsymbol{b}}^{c 1}\right\} \\
\left\{\overline{\boldsymbol{b}}^{c 2}\right\}
\end{array}\right\}
$$

If there are two regions that can be coupled using the MPC method, a relationship between various degrees of freedom may be expressed as $\bar{a}_{i}^{c 1}=\bar{a}_{j}^{c 2}$. One can write a linear transformation $[\boldsymbol{T}]$ linking all degrees of freedom $\left(\left\{\overline{\boldsymbol{a}}^{c 1}\right\}\right.$ and $\left.\left\{\overline{\boldsymbol{a}}^{c 2}\right\}\right)$ to a unique vector with effective degrees of freedom $\left\{\overline{\boldsymbol{a}}^{g}\right\}$

$$
\left\{\begin{array}{l}
\left\{\delta \overline{\boldsymbol{a}}^{c 1}\right\} \\
\left\{\delta \overline{\boldsymbol{a}}^{c 2}\right\}
\end{array}\right\}=[\boldsymbol{T}]\left\{\delta \overline{\boldsymbol{a}}^{g}\right\}
$$


The linear system concerning all effective degrees of freedom reads

$$
\left[\boldsymbol{M}^{g}\right]\left\{\delta \overline{\boldsymbol{a}}^{g}\right\}=\left\{\overline{\boldsymbol{b}}^{g}\right\}
$$

with

$$
\left[\boldsymbol{M}^{g}\right]=[\boldsymbol{T}]^{\top}\left[\begin{array}{cc}
{\left[\boldsymbol{M}^{c 1}\right]} & \mathbf{0} \\
\mathbf{0} & {\left[\boldsymbol{M}^{c 2}\right]}
\end{array}\right][\boldsymbol{T}] \quad \text { and } \quad\left\{\overline{\boldsymbol{b}}^{g}\right\}=[\boldsymbol{T}]^{\top}\left\{\begin{array}{l}
\left\{\overline{\boldsymbol{b}}^{c 1}\right\} \\
\left\{\overline{\boldsymbol{b}}^{c 2}\right\}
\end{array}\right\}
$$

Vertical misplacement of the mesh boundaries on the two perpendicular analyzed faces of the specimen may lead to artifacts after coupling the displacements of nodes belonging to the common edge, thereby resulting in inaccurate displacement fields (see Fig. 8). To solve this problem, the optimization of the position of the mesh boundaries was conducted. The cost function given in Eq.(14) is based on the minimization of the global mismatch strain of the elements that contain a constrained node, as a shift in the position of the mesh boundaries causes spurious shear strains in these elements

$$
e_{s}=\sum_{j}^{N_{i m}} \sum_{i}^{N_{e}} \frac{\left[\epsilon_{12}^{(i, j)}\right]^{2}}{\gamma_{s}^{2}}
$$

where $\epsilon_{12}$ denotes the (nodal) shear strain, $\gamma_{s}$ the shear strain uncertainty estimated from ten images acquired before the test when the specimen was pre-loaded, $N_{i m}$ the number of images, and $N_{e}$ the number of elements that contain constrained nodes.

\section{Identification framework}

In this study, Finite Element Model Updating (FEMU) is chosen as an identification method. FEMU is an approach to calibrate material parameters involved in mechanical tests by the development of an FE model of the mechanical test, and its comparison with experimental data [28, 31, 45]. The algorithm uses the results of DIC in FE models to minimize 
the distance between measured and predicted quantities. It is chosen to use the experimental geometry and the measured displacement fields as prescribed Dirichlet boundary conditions on the edges of the FE model. The cost function for the so-called FEMU-F route is based on the differences between measured and computed reaction forces

$$
\chi_{F}^{2}(\{\boldsymbol{p}\})=\frac{1}{\gamma_{F}^{2} n_{t}} \sum_{t}\left(F_{m}(t)-F_{c}(t,\{\boldsymbol{p}\})\right)^{2}
$$

where $\gamma_{F}$ is the load uncertainty (on $F_{m}$ ), $n_{t}$ the number of time increments, and $F_{c}$ the computed reaction forces, which depend on material parameters gathered in the column vector $\{\boldsymbol{p}\}$. The identification methodology consists in a nonlinear least-squares minimization of this cost function.

Considering the current set of parameters $\left\{\boldsymbol{p}_{n}\right\}$ at iteration $n$, the minimization is performed by calculating the correction $\{\delta \boldsymbol{p}\}$ from the linearized computed forces $F_{c}$

$$
F_{c}\left(t,\left\{\boldsymbol{p}_{n}\right\}+\{\delta \boldsymbol{p}\}\right) \approx F_{c}\left(t,\left\{\boldsymbol{p}_{n}\right\}\right)+\frac{\partial F_{c}}{\partial\{\boldsymbol{p}\}}\left(t,\left\{\boldsymbol{p}_{n}\right\}\right)\{\delta \boldsymbol{p}\}
$$

about the current estimate $\left\{\boldsymbol{p}_{n}\right\}$ of the sought parameters. The cost function then becomes

$$
\chi_{F}^{2}(\{\delta \boldsymbol{p}\})=\frac{1}{\gamma_{F}^{2} n_{t}} \sum_{t}\left(F_{m}(t)-F_{c}\left(t,\left\{\boldsymbol{p}_{n}\right\}\right)-\frac{\partial F_{c}}{\partial\{\boldsymbol{p}\}}\left(t,\left\{\boldsymbol{p}_{n}\right\}\right)\{\delta \boldsymbol{p}\}\right)^{2}
$$

and its minimization with respect to $\{\delta \boldsymbol{p}\}$ leads to a linear system

$$
[\boldsymbol{H}]\{\delta \boldsymbol{p}\}=\{\boldsymbol{h}\}
$$


164 where $[\boldsymbol{H}]$ is the Hessian

$$
[\boldsymbol{H}]=\sum_{t}\left(\frac{\partial F_{c}}{\partial\{\boldsymbol{p}\}}\left(t,\left\{\boldsymbol{p}_{n}\right\}\right)\right)^{\top} \frac{\partial F_{c}}{\partial\{\boldsymbol{p}\}}\left(t,\left\{\boldsymbol{p}_{n}\right\}\right)
$$

$165\{\boldsymbol{h}\}$ the right-hand member

$$
\{\boldsymbol{h}\}=\sum_{t}\left(\frac{\partial F_{c}}{\partial\{\boldsymbol{p}\}}\left(t,\left\{\boldsymbol{p}_{n}\right\}\right)\right)^{\top}\left(F_{m}(t)-F_{c}\left(t,\left\{\boldsymbol{p}_{n}\right\}\right)\right.
$$

166

167 168

and $\frac{\partial F_{c}}{\partial\{\boldsymbol{p}\}}\left(t,\left\{\boldsymbol{p}_{n}\right\}\right)$ the so-called sensitivity vector [46].

Three different FEMU-F approaches were used in this study (Table 3) using Abaqus [38] FE code and Correli 3.0 framework [4] for DIC analyses. 
Table 3 Summary of the three different FEMU-F approaches

\begin{tabular}{|c|c|c|c|c|}
\hline $\begin{array}{l}\text { Type of } \\
\text { analysis }\end{array}$ & Coupled & $\begin{array}{c}\text { Mesh } \\
\text { boundary } \\
\text { correction }\end{array}$ & $\begin{array}{l}\text { Input for } \\
\text { identification }\end{array}$ & FE model \\
\hline $\begin{array}{l}\text { Classical } \\
\text { (plane stress }\end{array}$ & ) & $\checkmark$ & $\begin{array}{l}\text { Average strain } \\
\text { (DIC gauge) }\end{array}$ & $\begin{array}{c}1 \text { four-noded element } \\
\text { (CPS4) }\end{array}$ \\
\hline $\begin{array}{l}\text { 2D Plane } \\
\text { Stress }\end{array}$ & $x$ & $\checkmark$ & $\begin{array}{l}\text { Prescribed DIC } \\
\text { displacements on } \\
\text { boundaries }\end{array}$ & $\begin{array}{l}170 \text { three-noded } \\
\text { elements (CPS3) }\end{array}$ \\
\hline $\begin{array}{c}\text { 3D } \\
\text { Coupled }\end{array}$ & $\checkmark$ & $\checkmark$ & $\begin{array}{c}\text { Prescribed DIC } \\
\text { displacement on } \\
\text { boundaries + } \\
\text { extrapolations }\end{array}$ & $\begin{array}{l}490 \text { eight-noded brick } \\
\text { elements (C3D8) }\end{array}$ \\
\hline
\end{tabular}

First, a "classical" analysis was conducted using a virtual DIC strain gauge (i.e., averaging the axial strain results over the DIC mesh). An FE model with one element was used to fit the constitutive law with the experimental stress-strain curve. Prescribed displacements were applied, as depicted in Fig. 4, to reach the same average strains as measured by DIC. Assuming uniform stress states, the resultant force was calculated and compared to the experimental load. With this approach, a FEMU-F scheme can be used to calibrate the material parameters. 


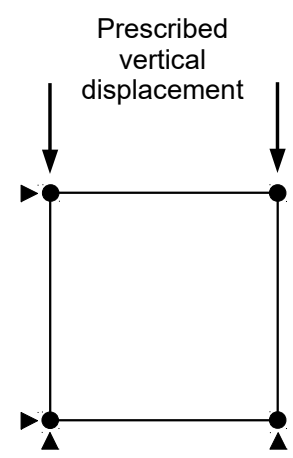

Figure 4 One-element model to calibrate material parameters via FEMU-F using uniform stress assumption

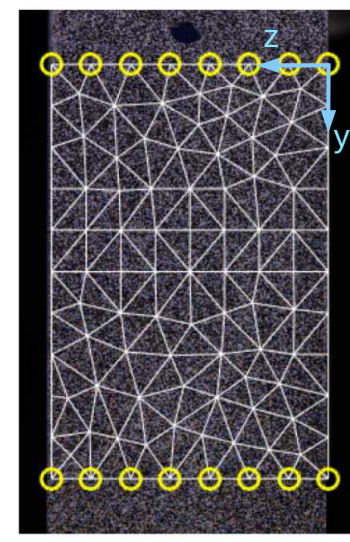

(a)

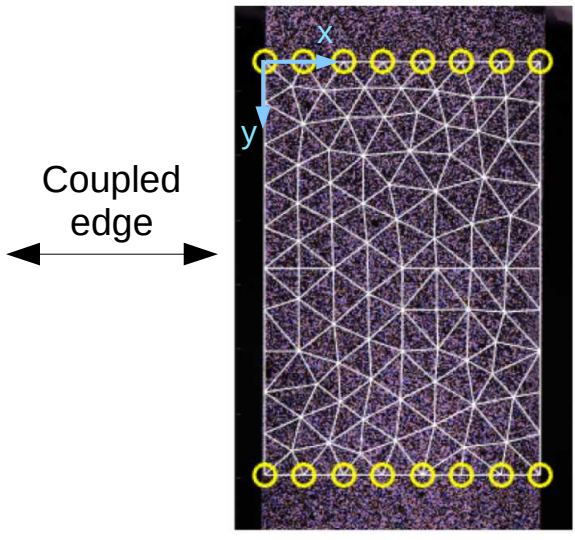

(b)

Figure 5 Reference images with mesh and boundary conditions applied in the 2D Plane Stress analysis of faces $y-z(\mathrm{a})$ and $x-y(\mathrm{~b})$. The ROI dimensions where the mesh is defined are $\approx 30 \mathrm{~mm}$ in height and $\approx 20.3 \mathrm{~mm}$ in width

In the 3D Coupled analysis, a hexahedron-element mesh was adopted. The vertical dis- 
placements were applied all over the cross-section of the upper and lower boundaries of the ROIs. For this purpose, the displacement fields obtained from DIC runs with MPC (Section 3) were used to fit, for the sake of simplicity, a plane. These results were then extrapolated for the vertical displacements inside the considered cross-sections of the specimen. Figure 6 shows these extrapolations for the first four force peaks (Fig. 2), following the coordinate system defined in Fig. 1 (i.e., the vertical axis $y$ is positive downward). The coefficients of the fitted planes were used as non-uniform distributions of displacement in the FE model. This approach allows the bending effect in the specimen to be represented as a measured displacements may induce nonuniform strain distributions.

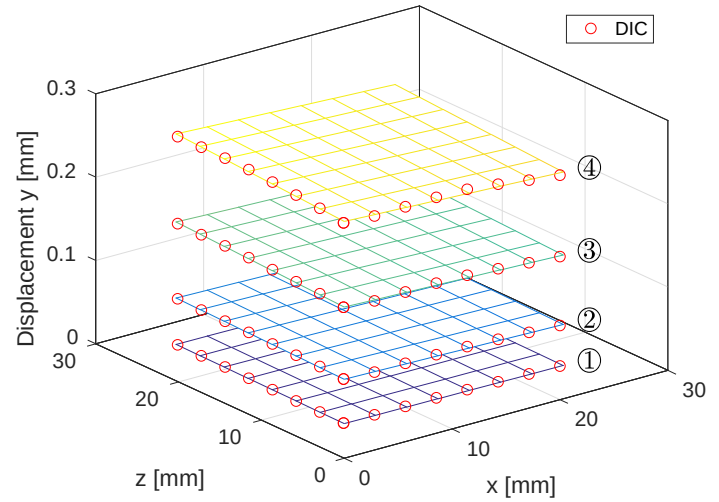

(a)

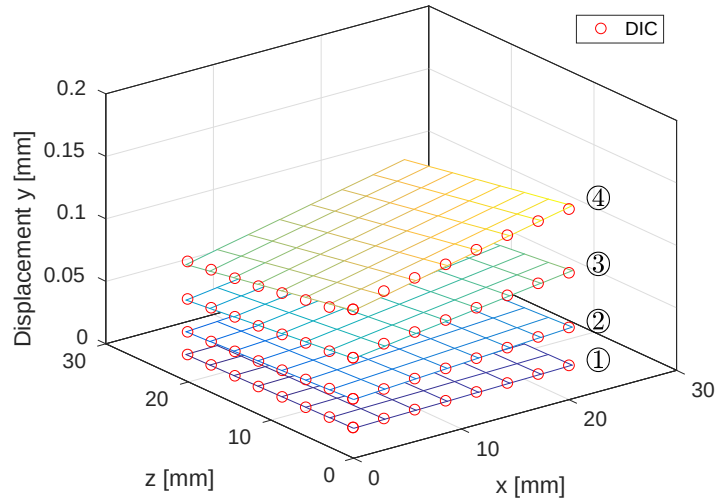

(b)

Figure 6 Extrapolated boundary conditions for the first four force peaks of (1) to (4)): (a) top and (b) bottom surfaces of the 3D model. The red circles depict measured quantities by DIC

\section{Results}

Section 5.1 shows the results of the DIC analysis and compares the use or not of the multi-point constraint (MPC) technique. A FEMU-F analysis using DIC data as virtual strain gauges (Classical) is shown in Section 5.2. Then, 2D Plane Stress FEMU-F analyses conducted for both faces independently are compared with the previous one in terms of 
calibrated parameters (Section 5.3). Last, the 3D Coupled FEMU-F analysis using DIC and MPC techniques is discussed in the Section 5.4 .

\subsection{Digital image correlation and multi-point constraint}

The images were processed using the Correli 3.0 framework [47] in which the additional steps described above were added. Table 4 shows the DIC analysis parameters. Displacement and strain noise-floor levels were calculated by the average of temporal standard deviation of all nodes and elements, respectively, when ten images were analyzed. They were acquired once the sample was mounted and the servohydraulic system was active. Strictly speaking, such uncertainties are no longer noise-floor estimates since they include the fluctuations associated with the hydraulic system. This observation is confirmed by studying the ratio between displacement and strain uncertainties (i.e., about 1230). It is expected that the ratio of the noise-floor estimates would be equal to the element length (i.e., 128 on average) [48]. This ten time increase of the displacement fluctuations was already observed when dealing with servohydraulic testing machines [49]. Interestingly, such displacement fluctuations, which are rigid body motions, have a very small impact on the strain fluctuations. 
Table 4 DIC analysis parameters

\begin{tabular}{|l|l|}
\hline \hline DIC software & Correli 3.0 [4] \\
Element length & RGB2gray \\
Shape functions & $124 \mid 133$ pixels (camera 1 | 2) \\
Mesh & linear (T3) \\
Matching criterion & unstructured (see Fig. 5) \\
Interpolant & sum of squared differences (Eq. (2)) \\
Displacement uncertainty & 0.16 pixel \\
Strain calculation & derivative of shape functions \\
Strain uncertainty & $1.3 \times 10^{-4}$ \\
\hline \hline
\end{tabular}

The displacement fields for both surfaces of the specimen under a compressive axial force of $620 \mathrm{~N}$ (first peak force (1), see Fig. 2 at time $\approx 50 \mathrm{~s}$, image 8) are shown in Fig. 7. The physical size of one pixel was $42.7 \mu \mathrm{m}$ for face $y-z$ and $45.9 \mu \mathrm{m}$ for face $x-y$. DIC is a full-field technique that also allows checking the "quality" of the test (i.e., how close it is to a priori assumed boundary conditions). In uniaxial compression, for example, the vertical displacement contours should be horizontal to comply with the hypotheses that the strain and stress fields should be homogeneous before cracks initiate. Figure 7 shows that the vertical displacement fields are not satisfying this condition. The inclined contours evidence the presence of bending of the sample during the test. Bending may have find its origin in the causes already described in Section 1. A nonuniform stress distribution is a consequence of bending, which may make the Classical approach inaccurate to treat the results. It is worth noting that bending may be a consequence of material heterogeneities. However, the pressing procedure used herein to manufacture the sample minimizes such heterogeneity. Moreover, 
a local heterogeneous behavior can be seen if the representative elementary volume is not respected. To avoid this artifact, a specimen with dimensions much larger than the average granule size of the powder (about $75 \mu \mathrm{m}$ [11) was used. Local heterogeneities would also lead to a considerable non-smooth displacement field, which was not observed in this study.

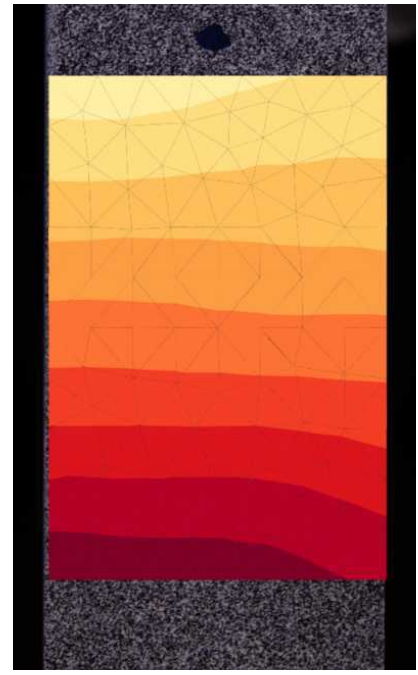

Camera 1

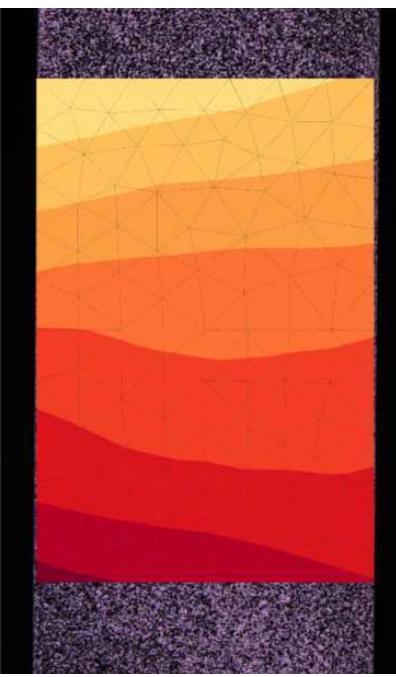

Camera 2

Figure 7 Vertical displacement fields (positive downward, expressed in $\mu \mathrm{m}$ ) using independent DIC analyses for faces $y-z$ and $x-y$

In spite of the displacement fields measured from faces $y-z$ and $x-y$, (Fig. 7) showing the same tendency, the displacement levels on the common edge of the sample (right edge $y-z$ and left edge $x-y$ ) are slightly different. By using the approach described in Section 3 , the displacement field can be measured by prescribing the equality of the vertical displacements of both faces of the shared edge (MPC technique). Figure 8 shows the DIC results using this approach. A continuous vertical displacement field is observed for both faces, which means the technique successfully coupled the vertical degrees of freedom of the common edge in the two images. However, a numerical artifact emerges in this region, which is evidenced by the appearance of fluctuations in the form of "waves" in the displacement field. This artifact 

positioned by visual inspection.

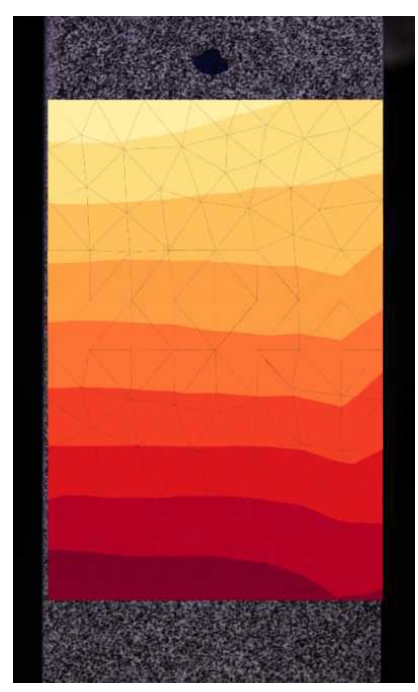

$y-z$ face
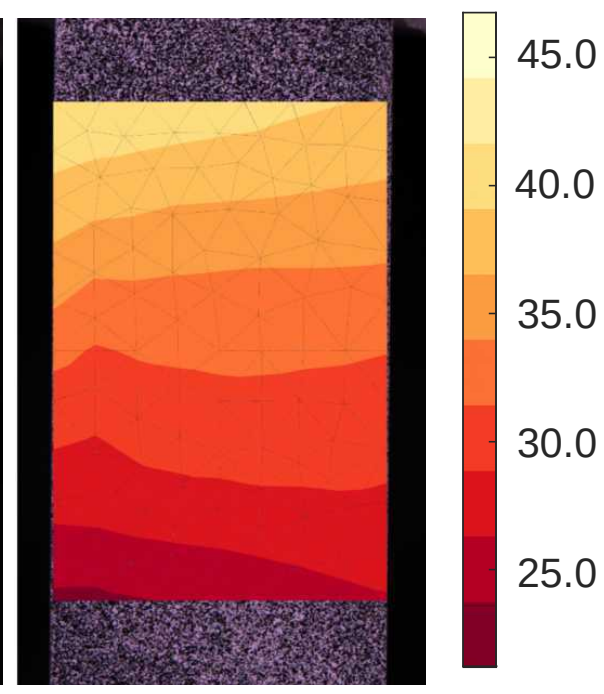

$x-y$ face

Figure 8 Vertical displacement fields of faces $y-z$ and $x-y$ (positive downward, expressed in $\mu \mathrm{m})$ when the constraints of equal vertical displacements is prescribed on the common edge

is a consequence of a vertical misplacement of the mesh boundaries, which were initially

To solve this problem, the optimization of the mesh boundary positions was performed by varying the vertical position of one mesh with respect to the other one. The result of the minimization of Eq. (14) showed that the meshes had to be shifted by a relative vertical displacement of $1.48 \mathrm{~mm}$ (i.e., $\approx 64$ pixels). The visual positioning of mesh boundaries was estimated to be in the yellow box of Fig. 9(a), and its optimization is depicted in white. Figure 9(b) shows the "shear" cost function (Eq. (14)) against the vertical mesh boundary translation about the optimal position. A smooth parabolic shape is observed and its minimum is close to unity, which means that the shear strain uncertainty $\gamma_{s}$ is reached. 


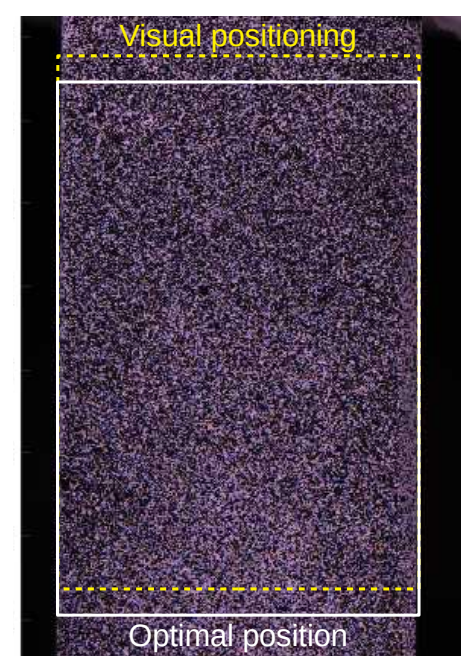

(a)

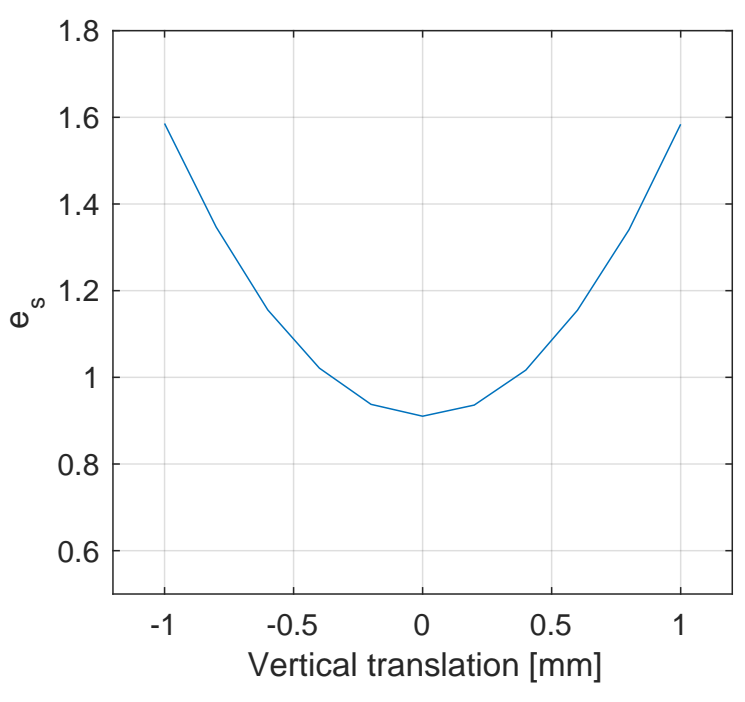

(b)

Figure 9 (a) Initial visual positioning of mesh boundaries (yellow) and after optimization (white). (b) Cost function $e_{s}$ vs. vertical translation of mesh on $x-y$ face

Figure 10 shows the displacement field with the corrected mesh position. The artifact is less pronounced and the displacement field is smoother than in the previous case.

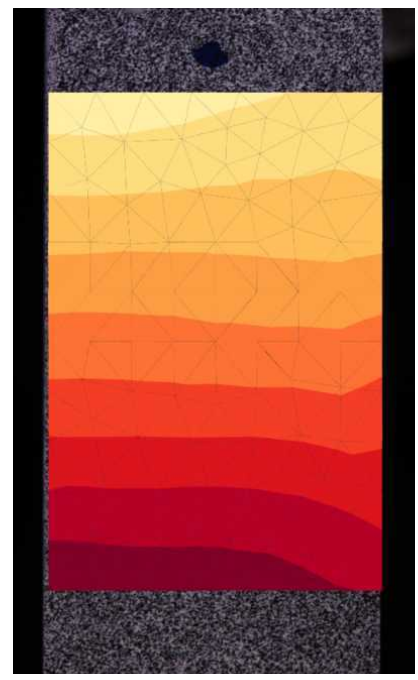

$y$-z face

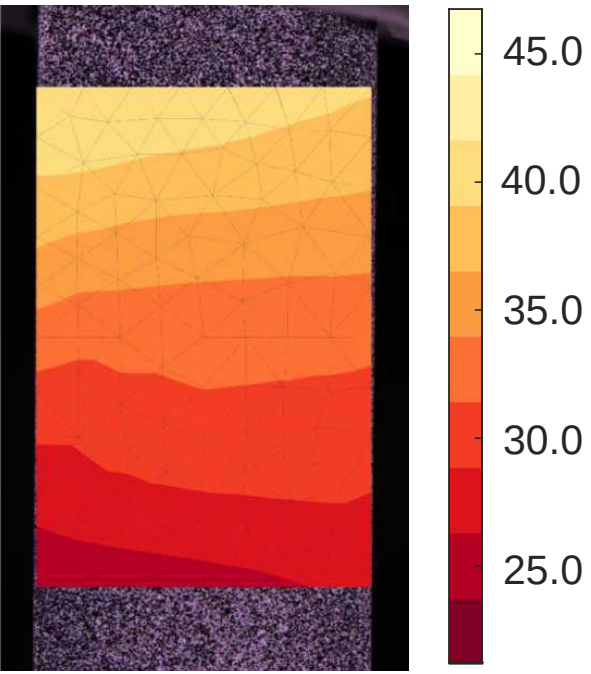

$x-y$ face

Figure 10 Vertical displacement fields for faces $y-z$ and $x-y$ (positive downward, expressed in $\mu \mathrm{m})$ when the constraints of equal vertical displacements is prescribed on the common edge and the meshes were repositioned 
This methodology made possible an analysis of both images in a more consistent way, allowing the use of the displacement fields for FEMU-F optimization with considerations of three dimensions. The corrected mesh was used in all identification approaches. The correction is the most influential in the three-dimensional coupled analysis.

\subsection{Classical FEMU-F analysis}

By the use of a FEMU-F approach, the Young's modulus $E$, yield stress $\sigma_{y}$, hardening coefficient $b$, and compressive strength $\sigma_{\infty}$ were identified using the ROI of DIC as a virtual gauge for the sequence of images of $y-z$ and $x-y$ faces independently. Before running the FEMU-F procedure, a sensitivity analysis was conducted (see Appendix A). The identifiability of the sought parameters was checked (and confirmed) for the considered experiment.

Figure 11 shows the stress-strain responses for axial strains obtained from independent DIC analyses. From the full-field measurements, the axial strains were evaluated averaging the engineering strain measure of DIC mesh elements (Fig. 5p). The numerical results were derived from a one-element $\mathrm{FE}$ model. The difference between experimental curves of $y-z$ and $x-y$ faces (Fig. 11) are due to bending of the specimen, which should be better captured using the three-dimensional model of Section 5.4 . 


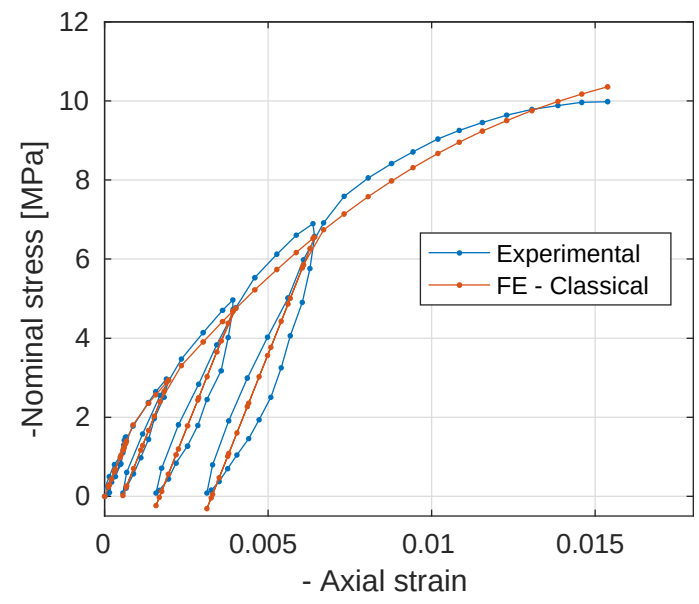

(a)

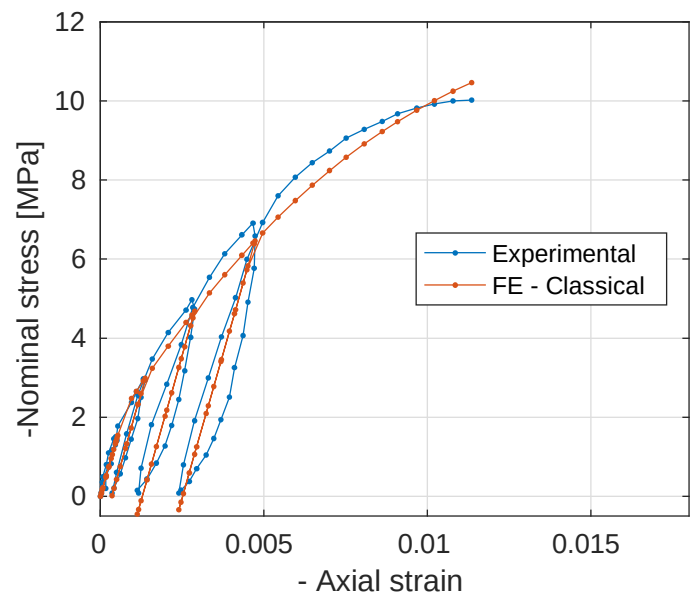

(b)

Figure 11 Classical (independent) analyses using DIC as a virtual strain gauge. Experimental and numerical stress-strain curves for (a) $y-z$ face, and (b) $x-y$ face

The difference between computed and measured loads, namely load residuals, are reported in Fig. 12. Their levels are similar for both faces, which is shown by the calculation of the root mean square (RMS) differences, namely $223 \mathrm{~N}$ (or $0.54 \mathrm{MPa}$ ) for the $x-y$ face, and $173 \mathrm{~N}$ (or $0.42 \mathrm{MPa}$ ) for the $y-z$ face. After the first two cycles, the residuals increase significantly, in other words, mostly in the plastic regime (Fig. 12). These cycles of loading and unloading have a better agreement between computed and measured forces, thereby highlighting that the selected elastic model cannot fully capture the unloading and reloading sequences of the last three cycles. Damage may explain such differences. The equivalent error (in RMS sense) for both faces is equal to $200 \mathrm{~N}$, much higher than the load uncertainty, which evidences that this error has its source in the numerical and material models chosen herein. 


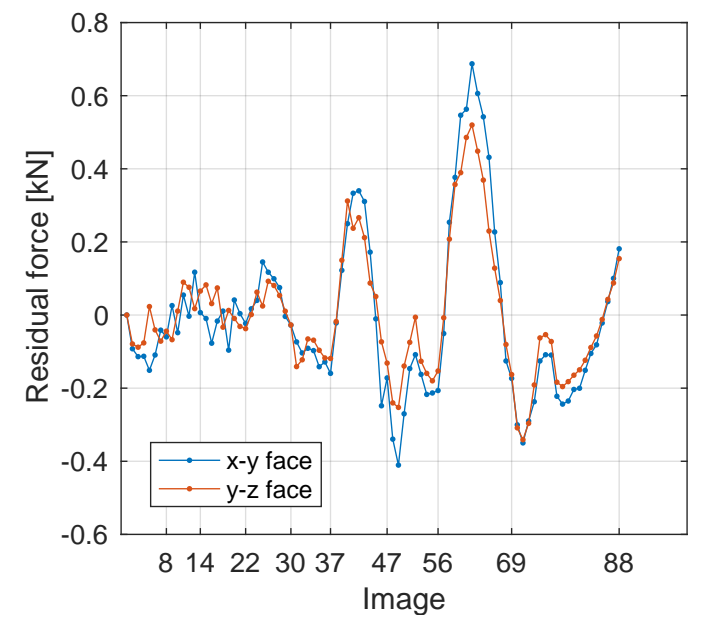

Figure 12 Load residuals for $x-y$ and $y-z$ faces

The values of the calibrated parameters are gathered in Table 5. The differences in levels for each face are mostly related to the assumption of homogeneous stress states in the specimen, which is not a good representation for this test.

Table 5 Calibrated parameters for Classical FEMU-F analysis

\begin{tabular}{cccc}
\hline Parameters & $x-y$ face & $y-z$ face & Average \\
\hline $\mathrm{E}[\mathrm{GPa}]$ & 2.9 & 2.1 & 2.5 \\
$\sigma_{y}[\mathrm{MPa}]$ & 2.3 & 2.0 & 2.1 \\
$\sigma_{\infty}[\mathrm{MPa}]$ & 12.4 & 11.6 & 12.0 \\
$\mathrm{~b}[-]$ & 212 & 199 & 206 \\
\hline
\end{tabular}

\subsection{D Plane Stress FEMU-F analysis}

By using boundary conditions measured via DIC, a plane stress analysis was performed for both faces independently. In this analysis, a non-homogeneous stress state can be achieved and bending effects partly taken into account. The same constitutive parameters as in the previous analysis were inspected. A sensitivity analysis was also performed for all images of 
the test and the results were similar as before (Appendix A). In Fig. 13, experimental and numerical forces are compared for $y-z$ and $x-y$ faces. A good agreement is observed.

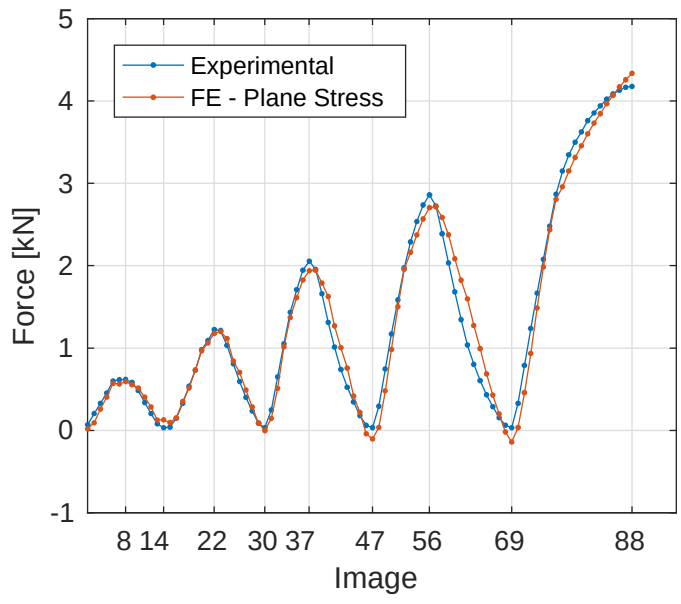

(a)

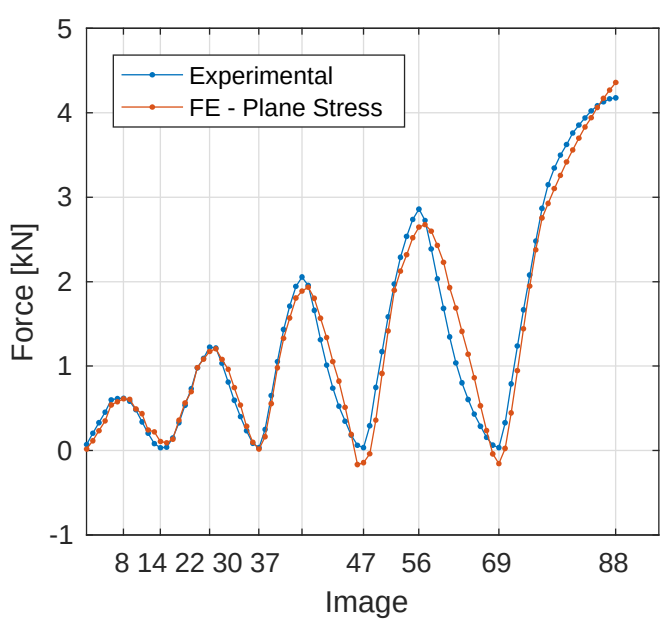

(b)

Figure 13 Plane stress analyses using measured boundary conditions. Experimental and computed forces for (a) $y-z$ and (b) $x-y$ faces

The difference between computed and measured forces are also very similar for both faces. The RMS values for the residual forces were evaluated as $221 \mathrm{~N}$ for $x-y$ face and $175 \mathrm{~N}$ for $y-z$ face. In the present case, the equivalent RMS error is $199 \mathrm{~N}$, a value very close to that obtained in the previous analysis, which means that there was no significant improvement in the representation of the problem by the numerical model. 


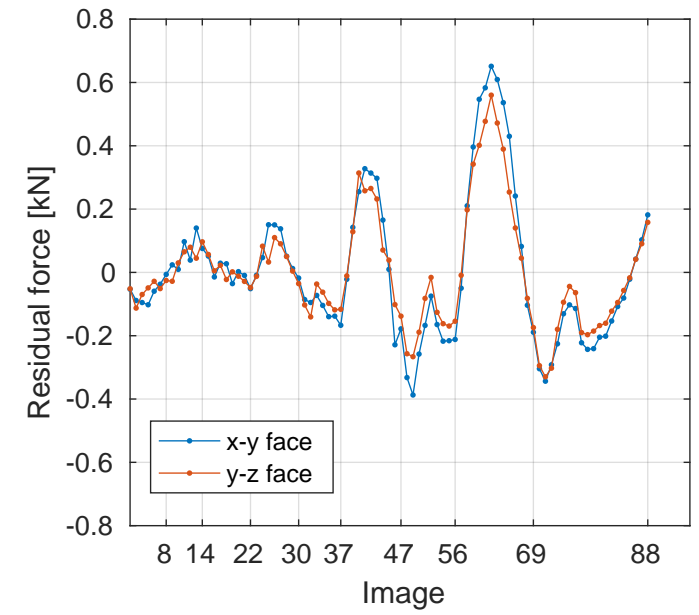

Figure 14 Force residuals for the plane stress analyses

Table 6 shows the two sets of parameters obtained for $y-z$ and $x-y$ faces. The gap between numerical and experimental data was minimized iteratively by the FEMU-F method (Fig. 13). However, there is a lack of agreement between the calibrated parameters for the two analyses, showing that the plane stress assumption was not sufficient to treat this problem. In the present case, bending has a three-dimensional nature, making inaccurate the previous assumption. Most of calibrated parameters were slightly closer to each other in comparison with the classical approach (Table 5), which may be related to the consideration of the bending effect in each face separately thanks to the plane stress analysis.

Table 6 Calibrated parameters for 2D Plane Stress FEMU-F analyses

\begin{tabular}{cccc}
\hline Parameters & $x-y$ face & $y-z$ face & Average \\
\hline $\mathrm{E}[\mathrm{GPa}]$ & 2.9 & 2.2 & 2.6 \\
$\sigma_{y}[\mathrm{MPa}]$ & 2.2 & 2.0 & 2.1 \\
$\sigma_{\infty}[\mathrm{MPa}]$ & 12.8 & 11.9 & 12.3 \\
$\mathrm{~b}[-]$ & 209 & 197 & 203 \\
\hline
\end{tabular}




\subsection{D Coupled FEMU-F analysis}

The 3D FEMU-F analysis used the data obtained from DIC using a multi-point constraint approach to couple the vertical DOFs on the shared edge of the specimen. On the top and bottom boundaries, the DIC data were extrapolated as described in Section 5.1. Sensitivities and the Hessian matrix are again very similar to those of the other two methods (Appendix A). The experimental and computed forces are reported in Fig. 15(a), and the corresponding residual forces in Fig. 15(b). The residual forces are similar for 3D and plane stress analyses, the RMS of the residual force for the present case is $191 \mathrm{~N}$, which is lower than the values of the previous two analyses, thereby showing that the 3D consideration of the bending effect is an improvement in the numerical representation of the mechanical test.

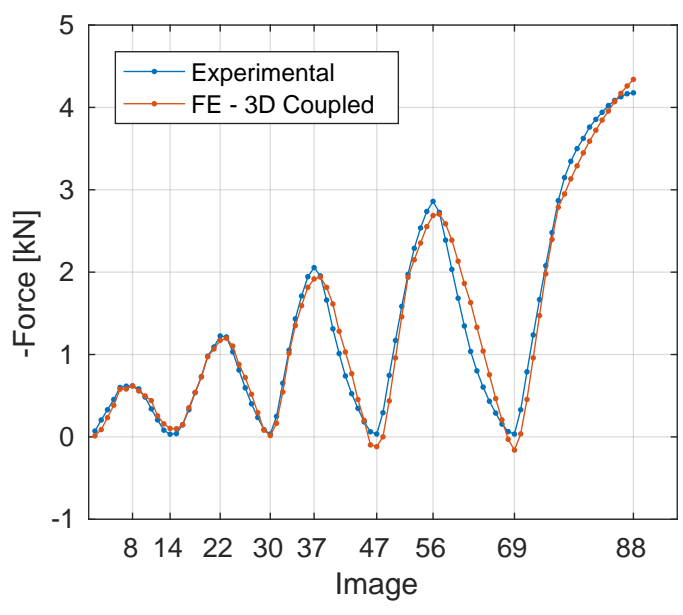

(a)

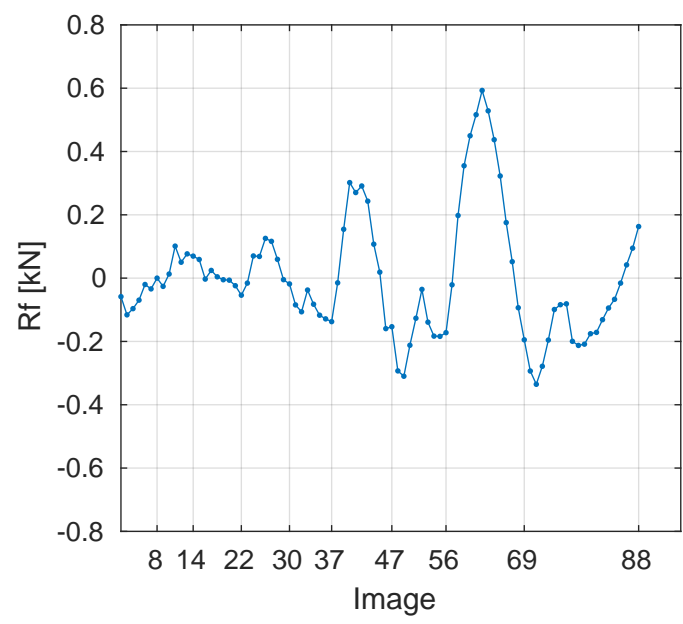

(b)

Figure 15 (a) Experimental and computed forces, and (b) corresponding residuals for the 3D Coupled FEMU-F analysis

The minimization of the gap between computed and experimental data by the 3D Coupled FEMU-F algorithm resulted in yet another set of parameters in comparison with the previous analyses (Table 7). It is interesting to note that their levels lie between those previously found and close, but not identical, to their averages. 
Table 7 Calibrated parameters for 3D FEMU-F analysis

\begin{tabular}{cc}
\hline Parameters & 3D FEMU-F \\
\hline $\mathrm{E}[\mathrm{GPa}]$ & 2.5 \\
$\sigma_{y}[\mathrm{MPa}]$ & 2.0 \\
$\sigma_{\infty}[\mathrm{MPa}]$ & 12.4 \\
$\mathrm{~b}[-]$ & 207 \\
\hline
\end{tabular}

From the load distribution obtained in the FE model, it was possible to calculate the load eccentricity (i.e., the point where the resultant moment vanishes) in directions $x$ and $z$ (Fig. 16). Small eccentricities are observed in both directions. However, neglecting them may lead to erroneous calibration of material parameters. For example, considering the parameters in the classical FEMU-F approach for the $x-y$ face, the Young's modulus is $15.4 \%$ higher in comparison with that obtained in this last analysis. It is important to note that care was taken to minimize the bending effect during the test, by the use of epoxy resin in the end portion of the specimen and checking the parallelism in the platens of the testing machine. Yet, even with such procedures, it was not possible to fully align the sample. Further, it is interesting to note that beyond the second cycle, the eccentricity does not evolve much. This phenomenon is related to the fact that the material is yielding and that this nonlinearity induces stress (and strain) redistributions that were not possible in the elastic regime. 


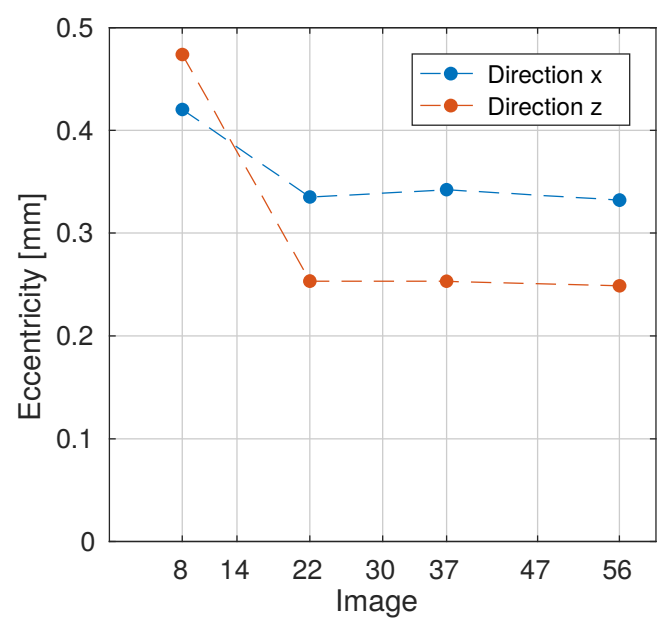

Figure 16 Eccentricity of the load distribution at loading peaks, expressed as distance from the center of the cross section

Figure 17(a) shows the FE results of the axial strain distribution in the ROI of the specimen for the last image (i.e., at maximum loading). Non-homogeneous strains are observed in the specimen. Moreover, the average value of axial strain is close to the diagonal of the cross-section that is related to the same magnitude of eccentricity shown in Fig. 16. The so-called percent bending [5] is a quantity defined as the difference between the strain on the surface and the nominal axial strain divided by the nominal axial strain. It is a measure of the goodness of uniaxial compression tests. Figure $17(\mathrm{~b})$ shows the average and standard deviation of the axial strains as functions of the image number. The two quantities are proportional to each other during the whole test. From such data, it is possible to calculate a maximum percent bending of 23, which is approximately 10 times higher than the recommended level (i.e., 2.5 [5]). 


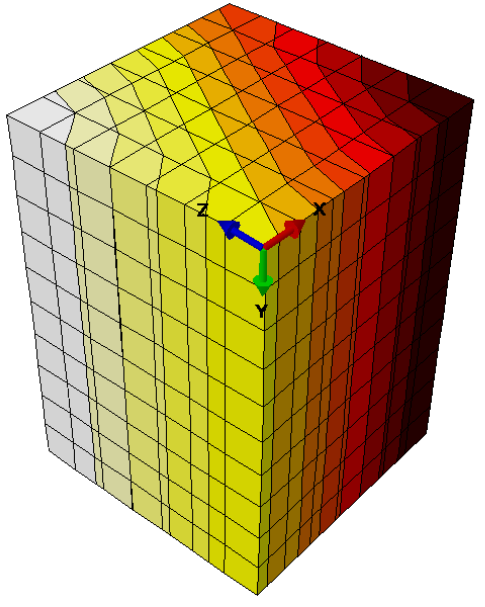

(a)

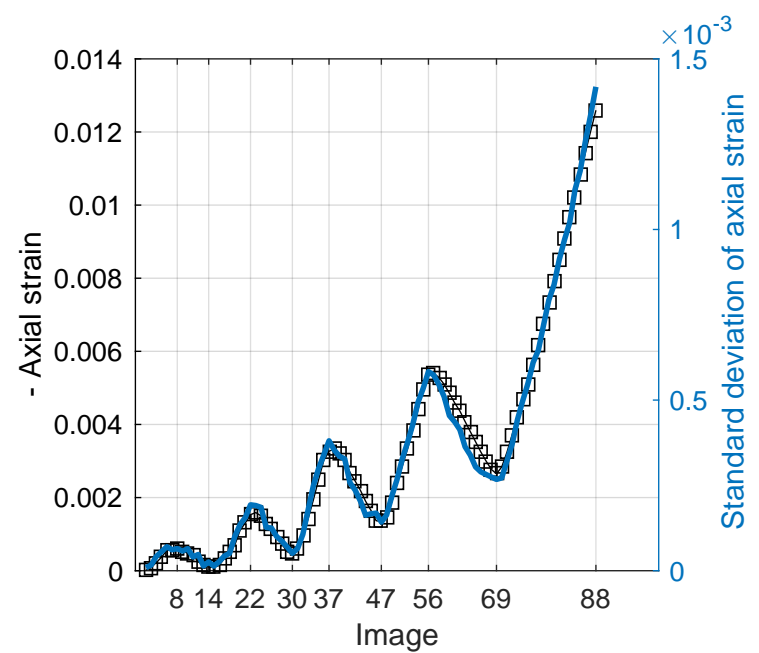

(b)

Figure 17 (a) Axial strain distribution in the FE model for the last image (88) and (b) Average (square symbols) and standard deviation (solid blue line) of axial strain vs. image number

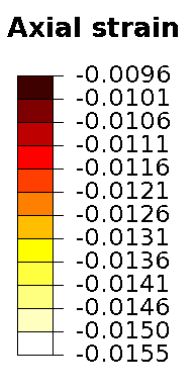

\section{Conclusions}

Some experimental artifacts in uniaxial compression tests may lead to spurious bending

effects, rendering inaccurate the usual assumption of uniform strain over the cross-section of the specimen. DIC measurements were conduced by using two cameras that captured images of two perpendicular free surfaces of the specimen. The multi-point constraint technique was used to couple the degrees of freedoms of the shared boundary of the images captured from both faces in a DIC framework.

A FEMU-F methodology was applied to calibrate the elastoplastic parameters of a Drucker-Prager model for three distinct cases:

- Classical approach where DIC was used as a virtual strain gauge and the constitutive model was fitted with the load-strain curve independently for the results of both faces;

- 2D Plane stress analysis where the boundary conditions were prescribed displacements obtained independently from DIC analyses; 
- 3D Coupled analysis where the multi-point constraint technique was used to join the results of DIC from image acquisitions of both faces, and extrapolation of the measured boundary conditions to two cross-sections.

As expected, the independent analyses for both faces (i.e., classical approach and plane-stress analyses, see Table 3 resulted in different sets of parameters as a consequence of the violation of the uniform strain assumption. As 2D Plane Stress analyses consider the bending effect in their plane, most of the calibrated parameters were closer to each other in comparison with the classical approach. The full consideration of the bending effect in the 3D Coupled analysis leads to a set of parameters that lies within the intervals of the parameters found from the previous two approaches. The average parameters of Classical and 2D Plane Stress analyses are also good approximations of the set of parameters obtained in the 3D analysis. However, the latter led to the lowest identification residuals. This observation shows that the 3D model better captures bending effects and leads to more trustworthy results.

The developed procedure permitted to check, measure and consider the bending effects in uniaxial compression tests and their analyses. The implemented procedure was applied to measure the displacement fields on two perpendicular lateral surfaces of the specimen. The use of two cameras is the minimum required to capture the parasite bending effect in both directions perpendicular to the loading axis. In return, the boundary conditions have to be extrapolated on the non-measured surfaces. The procedure can also be applied using a fourcamera system. In this case, the extrapolation would be only performed only for bulk nodes. It is worth noting that a multiview correlation framework [50] may have been used. It would not have required the use of multi-point constraint technique to measure the 3D surface displacement fields. However, it would involve a calibration step of the cameras. Last, the boundary conditions could themselves have been introduced as additional unknowns to the minimization problem [51. As a final perspective, a study with several specimens should be 
carried out to further evaluate the benefit of the newly developed procedure.

\section{Acknowledgments}

This study was financed in part by the Coordenação de Aperfeiçoamento de Pessoal de Nível Superior - Brasil (CAPES) - Finance Code 001, and the support by the grants \#130167/2018-5, National Council for Technological and Scientific Development - CNPq (Brazil) and \#2018/02801-4, \#2018/15266-0 and \#2018/25419-8, São Paulo Research Foundation (FAPESP).

\section{References}

[1] J. Gustkiewicz, Uniaxial compression testing of brittle rock specimens with special consideration given to bending moment effects, in: International Journal of Rock Mechanics and Mining Sciences \& Geomechanics Abstracts, Vol. 12, Elsevier, 1975, pp. 13-25.

[2] I. Hawkes, M. Mellor, Uniaxial testing in rock mechanics laboratories, Engineering Geology 4 (3) (1970) 179-285.

[3] S. D. Peng, Stresses within elastic circular cylinders loaded uniaxially and triaxially, in: International Journal of Rock Mechanics and Mining Sciences \& Geomechanics Abstracts, Vol. 8, Elsevier, 1971, pp. 399-432.

[4] G. Sines, M. Adams, Compression testing of ceramics, in: Flaws and Testing, Springer, 1978, pp. 403-434.

[5] Standard test method for monotonic compressive strength of advanced ceramics at ambient temperature, Tech. rep., ASTM International (2015). 
[6] R. Westerheide, K. A. Drüsedau, T. Hollstein, T. Schwickert, H. Zipse, Advances in characterisation of machined green compacts, Journal of the European Ceramic Society 17 (2-3) (1997) 467 - 472. doi:10.1016/S0955-2219(96)00174-4.

[7] O. Coube, H. Riedel, Numerical simulation of metal powder die compaction with special consideration of cracking, Powder Metallurgy 43 (2) (2000) 123-131.

[8] J. C. Cunningham, I. C. Sinka, A. Zavaliangos, Analysis of tablet compaction. i. characterization of mechanical behavior of powder and powder/tooling friction, Journal of Pharmaceutical Sciences 93 (8) (2004) 2022-2039. doi:\{10.1002/jps.20110\}.

[9] V. Mazel, H. Diarra, V. Busignies, P. Tchoreloff, Comparison of different failure tests for pharmaceutical tablets: Applicability of the drucker-prager failure criterion, International journal of pharmaceutics 470 (1-2) (2014) 63-69.

[10] H. Shin, J.-B. Kim, A numerical investigation on determining the failure strength of a powder compact in unconfined compression testing by considering the compressible character of the specimen, Powder Technology 277 (2015) 156-162.

[11] F. S. Montilha, F. O. Rocco, C. C. Melo, V. F. Sciuti, R. B. Canto, Identification of dilatancy in green compacted ceramic powder via digital image correlation, Powder Technology 330 (2018) 471-476.

[12] M. Grédiac, F. Hild, Full-field measurements and identification in solid mechanics, John Wiley \& Sons, 2012.

[13] F. Hild, S. Roux, Digital image correlation, in: P. Rastogi, E. Hack (Eds.), Optical Methods for Solid Mechanics. A Full-Field Approach, Wiley-VCH, Weinheim (Germany), 2012, pp. 183-228. 
[14] M. Sutton, Computer vision-based, noncontacting deformation measurements in mechanics: A generational transformation, Applied Mechanics Reviews 65 (AMR-13-1009) (2013) 050802.

[15] M. Sutton, W. Wolters, W. Peters, W. Ranson, S. McNeill, Determination of displacements using an improved digital correlation method, Im. Vis. Comp. 1 (3) (1983) 133139.

[16] M. A. Sutton, J. J. Orteu, H. Schreier, Image correlation for shape, motion and deformation measurements: Basic concepts, theory and applications, Springer Science \& Business Media, 2009.

[17] S. Roux, F. Hild, Y. Berthaud, Correlation image velocimetry: A spectral approach, Applied Optics 41 (1) (2002) 108-115.

[18] B. Wagne, S. Roux, F. Hild, Spectral approach to displacement evaluation from image analysis, European Physical Journal: Applied Physics 17 (2002) 247-252.

[19] G. Broggiato, Adaptive image correlation technique for full-field strain measurement, in: C. Pappalettere (Ed.), 12th Int. Conf. Experimental Mechanics, McGraw Hill, Lilan (Italy), 2004, pp. 420-421.

[20] Y. Sun, J. Pang, C. Wong, F. Su, Finite-element formulation for a digital image correlation method, Applied Optics 44 (34) (2005) 7357-7363.

[21] G. Besnard, F. Hild, S. Roux, "Finite-element" displacement fields analysis from digital images: Application to Portevin-Le Chatelier bands, Experimental Mechanics 46 (2006) 789-803. 
[22] H. Leclerc, J. Périé, S. Roux, F. Hild, Integrated digital image correlation for the identification of mechanical properties, in: A. Gagalowicz, W. Philips (Eds.), MIRAGE 2009, Vol. LNCS 5496, Springer, Berlin (Germany), 2009, pp. 161-171.

[23] S. Avril, M. Bonnet, A. Bretelle, M. Grédiac, F. Hild, P. Ienny, F. Latourte, D. Lemosse, S. Pagano, E. Pagnacco, F. Pierron, Overview of identification methods of mechanical parameters based on full-field measurements, Experimental Mechanics 48 (4) (2008) $381-402$.

[24] J. D. Collins, G. C. Hart, T. K. Hasselman, B. Kennedy, Statistical identification of structures, AIAA Journal 12 (2) (1974) 185-190.

[25] K. T. Kavanagh, Extension of classical experimental techniques for characterizing composite-material behavior, Experimental Mechanics 12 (1) (1972) 50-56.

[26] K. T. Kavanagh, R. W. Clough, Finite element applications in the characterization of elastic solids, International Journal of Solids and Structures 7 (1971) 11-23.

[27] K. Sun, Y. Zhao, H. Hu, Identification of temperature-dependent thermal-structural properties via finite element model updating and selection, Mechanical Systems and Signal Processing 52 (2015) 147-161.

[28] E. Pagnacco, D. Lemosse, F. Hild, F. Amiot, Inverse strategy from displacement field measurement and distributed forces using fea, in: 2005 SEM annual conference and exposition on experimental and applied mechanics, 2005.

[29] S. Cooreman, D. Lecompte, H. Sol, J. Vantomme, D. Debruyne, Elasto-plastic material parameter identification by inverse methods: Calculation of the sensitivity matrix, International Journal of Solids and Structures 44 (13) (2007) 4329-4341. 
[30] D. Lecompte, A. Smits, H. Sol, J. Vantomme, D. V. Hemelrijck, Mixed numericalexperimental technique for orthotropic parameter identification using biaxial tensile tests on cruciform specimens, International Journal of Solids and Structures 44 (5) (2007) 1643-1656.

[31] P. Ienny, A.-S. Caro-Bretelle, E. Pagnacco, Identification from measurements of mechanical fields by finite element model updating strategies: a review, European Journal of Computational Mechanics/Revue Européenne de Mécanique Numérique 18 (3-4) (2009) $353-376$.

[32] F. Mathieu, H. Leclerc, F. Hild, S. Roux, Estimation of elastoplastic parameters via weighted FEMU and integrated-DIC, Experimental Mechanics 55 (1) (2015) 105-119.

[33] Z. Tomičević, J. Kodvanj, F. Hild, Characterization of the nonlinear behavior of nodular graphite cast iron via inverse identification: Analysis of biaxial tests, European Journal of Mechanics-A/Solids 59 (2016) 195-209.

[34] R. Vargas, J. Neggers, R. B. Canto, J. A. Rodrigues, F. Hild, Analysis of a castable refractory using the wedge splitting test and cohesive zone model, Journal of the European Ceramic Society 39 (13) (2019) 3903-3914.

[35] K. Peng, J. Zhou, Q. Zou, J. Zhang, F. Wu, Effects of stress lower limit during cyclic loading and unloading on deformation characteristics of sandstones, Construction and Building Materials 217 (2019) 202-215.

[36] C. A. Felippa, Introduction to finite element methods, Course Notes, Department of Aerospace Engineeing Sciences, University of Colorado at Boulder, available at http://www.colorado.edu/engineering/Aerospace/CAS/courses.d/IFEM.d. 
[37] D. C. Drucker, W. Prager, Soil mechanics and plastic analysis or limit design, Quarterly Journal of Applied Mathematics 10 (2) (1952) 157-165.

[38] Dassault Systèmes Simulia Corp., Providence, RI, USA., Abaqus 6.14 Documentation (2014).

[39] C. C. Melo, A. L. I. Moraes, F. O. Rocco, F. S. Montilha, R. B. Canto, A validation procedure for numerical models of ceramic powder pressing, Journal of the European Ceramic Society 38 (8) (2018) 2928-2936. doi:https://doi.org/10.1016/j. jeurceramsoc.2018.01.009.

[40] E. Voce, The relationship between stress and strain for homogeneous deformation, Journal of the Institute of Metals 74 (1948) 537-562.

[41] O. Zienkievicz, R. Taylor, The Finite Element Method, 4th edition, McGraw-Hill, London (UK), 1989.

[42] B. Lucas, T. Kanade, An iterative image registration technique with an application to stereo vision, in: 7th International Joint Conference on Artificial Intelligence, 1981, pp. 674-679.

[43] L. Jendele, J. Červenka, On the solution of multi-point constraints-application to FE analysis of reinforced concrete structures, Computers \& Structures 87 (15-16) (2009) 970-980.

[44] R. D. Cook, D. S. Malkus, M. E. Plesha, Concepts and applications of finite element analysis, John Wiley \& Sons, 2007.

[45] M. Grédiac, F. Hild (Eds.), Full-Field Measurements and Identification in Solid Mechanics, ISTE / Wiley, London (UK), 2012. 
[46] A. Tarantola, Inverse Problems Theory. Methods for Data Fitting and Model Parameter Estimation, Elsevier Applied Science, Southampton (UK), 1987.

[47] H. Leclerc, J. Neggers, F. Mathieu, S. Roux, F. Hild, Correli 3.0, IDDN.FR.001.520008.000.S.P.2015.000.31500 (2015).

[48] F. Hild, S. Roux, Comparison of local and global approaches to digital image correlation, Experimental Mechanics 52 (9) (2012) 1503-1519.

[49] X. Fayolle, F. Hild, Controlling stress intensity factor histories with digital images, Experimental Mechanics 54 (2) (2014) 305-314.

[50] J.-E. Dufour, F. Hild, S. Roux, Shape, Displacement and Mechanical Properties from Isogeometric Multiview Stereocorrelation, Journal of Strain Analysis for Engineering Design 50 (7) (2015) 470-487.

[51] M. Bertin, C. Du, J. P. M. Hoefnagels, F. Hild, Crystal plasticity parameter identification with 3D measurements and integrated digital image correlation, Acta Materialia 116 (2016) 321-331. 


\section{Appendix A: Sensitivity Analysis}

The sensitivity analysis is part of the calculations performed in the FEMU-F procedure to check the identifiability of the sought parameters (Section 4). The load sensitivities were computed by using Eq. (21) for the three FEMU-F approaches described in this study (Table 3). The derivatives were estimated via forward differences with a perturbation factor $\alpha=10^{-2}$ of each parameter $\left(\Delta p_{i}=\alpha p_{i}\right)$

$$
S_{F i}\left(p_{i}, t\right)=\frac{\partial F_{c}}{\partial p_{i}}\left(p_{i}, t\right) \approx \frac{F_{c}\left(p_{i}+\Delta p_{i}, t\right)-F_{c}\left(p_{i}, t\right)}{\Delta p_{i}}
$$

Note that the variables described in Eq. (21) are the same as those used in Eq. (15).

Figure 18 shows the computed load sensitivities $\boldsymbol{S}_{F}$ for the different FEMU-F approaches, indicating the influence of the studied material parameters at the different steps of the test. The results of the sensitivity analysis are very similar between the independently analyzed faces (Figure 18(a-b)) and the different FEMU-F approaches. The elastic modulus increases its sensitivity at a higher rate in the elastic regions and a slower rate in the elastoplastic regime, following the loading curve shown in Fig. 2 .

All the parameters related to plasticity show no sensitivity in elasticity before first yielding (as expected). The yield stress $\sigma_{y}$ has a fast increase in sensitivity in the transition from elastic to plastic regimes, and then a slow decrease until the peak stress. The contribution of the hardening coefficient $b$ and compressive strength $\sigma_{\infty}$ become more important at the end of the test, where their sensitivities are higher. For all parameters, the load sensitivities are very high (in comparison with the load uncertainty of $4.5 \mathrm{~N}$ or the corresponding stress uncertainty of $11 \mathrm{kPa}$ ) for a one percent variation of each parameter. This result indicates that the parameters are expected to be identifiable for the considered test and proposed identication route. 

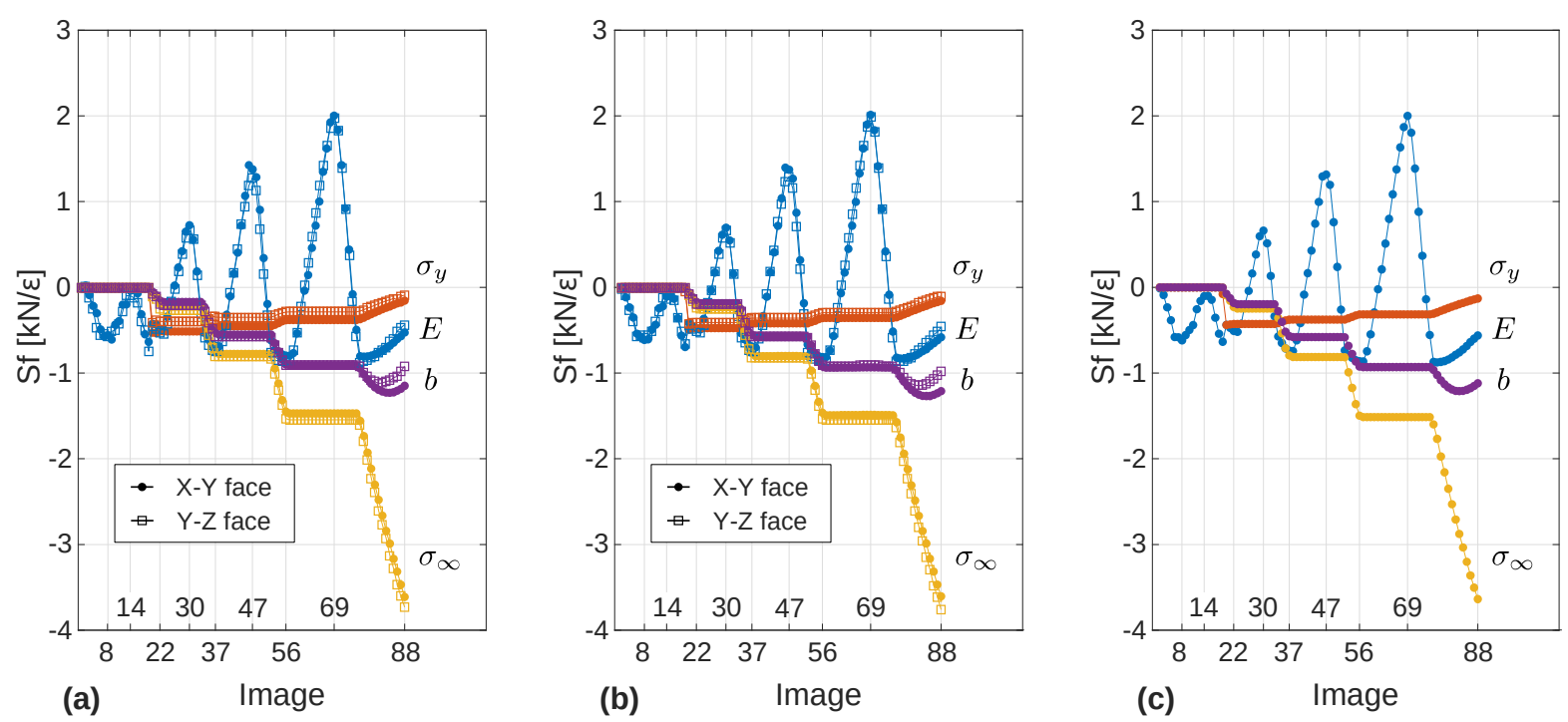

Figure 18 Computed load sensitivity for: (a) Classical analysis, (b) 2D Plane stress FEMU-F analysis and (c) 3D Coupled FEMU-F analysis.

Figure 19(a) shows the Hessian matrix in decimal logarithm for the Classical FEMU-F approach (see Eq. (19)). The sensitivity of the material parameters taken independently is related to the diagonal terms of the matrix. The off-diagonal terms represent the correlations between two parameters. The spectrum of eigen values (Fig. 19 (b)) is not very wide, which indicates that the overall conditioning of the Hessian matrix is very good, namely, all parameters should be identifiable. The most sensitive parameters are the hardening and Young's moduli (i.e., the third and fourth eigen vectors are mostly dependent on these two parameters), followed by the yield stress and then the ultimate strength. 


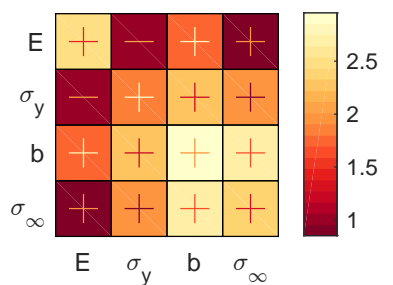

(a)

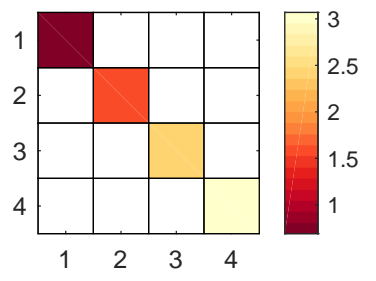

(b)

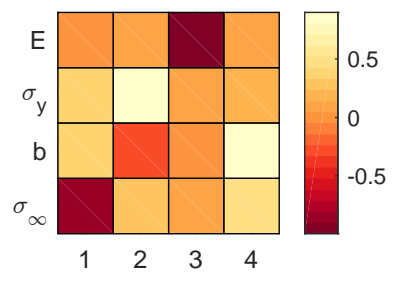

(c)

Figure 19 a) Hessian matrix in decimal logarithm for $x-y$ face in the classical FEMU-F analysis, (b) Decimal logarithm of the eigenvalues of Hessian matrix, and (c) corresponding eigenvectors.

As a consequence of very similar sensitivities for the FEMU-F approaches (Fig. 18), the Hessian matrix for the 2D Plane Stress and 3D Coupled approaches are also alike as shown in Figure 20.

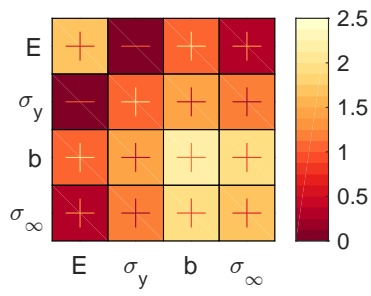

(a)

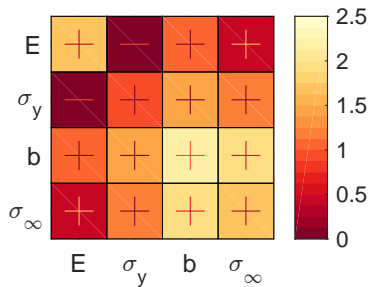

(b)

Figure 20 Hessian matrix in decimal logarithm for: (a) 2D Plane Stress and (b) 3D Coupled analyses. 